Background The hospice provides inpatient, outpatient and community services including a Continuing Healthcare (CHC) virtual ward. During COVID-19 the hospice suffered clinical staffing issues with immune-compromised staff isolating and volunteers unable to attend, while income-generation departments were furloughed. CHC beds were increased by $10 \%$ to facilitate hospital discharges.

Aims To enable the community team to continue to support palliative patients in their own homes and allow prompt discharge of hospital patients.

Method All furloughed staff were contacted and offered the opportunity to support the clinical teams. This included outpatient clinical staff and non-clinical staff. The education department delivered intensive training sessions including clinical mandatory training and core personal care skills leading to the role of Clinical Support Worker (CSW). However, working a trial shift for some proved too demanding emotionally, psychologically, or physically.

Results Caring for COVID-19 positive patients had a large psychological impact on the team. However, no COVID-19 transfer was identified from a patient or between colleagues. An occupational therapist assigned to the team empowered staff to utilise equipment to improve patient care. CSWs also supported other departments in-between with administration tasks where possible. The CSWs were included in all patient discussions and attended handovers, team meetings and were offered clinical supervision/debrief sessions.

Conclusion The community team continued to provide highquality palliative care services as contracted even through the fast-paced changes. Patients and their carers reported feeling supported. The 'walls' around different hospice teams began to disintegrate with an appreciation of how the teams are all working to meet the shared aims of excellent patient-centred care. The pandemic has united the community team and forged strong links with other hospice teams. The CSWs developed their care and communication skills and the whole team have shown themselves to be non-judgemental, enthusiastic, and proud to serve their community.

\section{P-73 SHARING IS CARING - PEER TO PEER EDUCATION}

Fiona Irvine. Ayrshire Hospice, Ayr, UK

10.1136/spcare-2021-Hospice.91

Background During the COVID-19 pandemic Ayrshire Hospice piloted a training course for personal carers in North Ayrshire focusing on palliative and end-of-life care. The course was delivered online, comprising four 90 minutes sessions. One of the sessions focused specifically on the practical aspects of carrying out personal care towards the end of a person's life, and featured a demonstration by two of the hospice's senior care assistants using a training mannequin.

Aims The pilot aimed to increase knowledge and understanding of the principles of palliative and end-of-life care for personal carers. The aim of this particular session was to share, peer to peer, the specialist knowledge and skills required in caring for someone towards the end of their life.

Methods During this particular session, two experienced senior care assistants gave a practical demonstration of how they would provide personal care for someone nearing the end of their life, using a mannequin. They shared the practical skills they employ, emphasising the importance of care being carried out gently and slowly, and discussed how they used this as an opportunity to simultaneously assess the person's condition; looking for any signs of distress, pain, issues regarding skin integrity and oral health.

Outcomes Sharing best practice through example peer to peer was well received. Ultimately this will benefit the people being cared for, whilst also building the skills and confidence of all involved. Links were formed, with the hospice now viewed as an invaluable resource. The online nature of the training proved successful, in terms of ease of access for participants, and the flexibility to include demonstrations from hospice team members. Sessions evaluated positively. Further training has since been progressed in North Ayrshire, with the hope that it will be adopted across Ayrshire over the next 18 months.

\section{P-74 FAMILY AND COMMUNITY SUPPORT SERVICE - THE COMPASSIONATE COMMUNITIES APPROACH}

Maz Kull, Marianne Grant. Compton Care, Wolverhampton, UK

10.1136/spcare-2021-Hospice.92

Background The Family and Community Support Service was developed in response to the COVID-19 pandemic. By bringing together the Community Development, Social Work, Bereavement and Psychological Therapies Teams with the intention of extending our reach into communities for people affected by COVID-19, not known to Compton Care or living with a complex or incurable condition.

Aims To provide a support service for communities impacted by COVID-19 and focusing on three specific areas of support:

1. Wellbeing and Bereavement - Virtual Bereavement Information Hubs; a suite of bereavement literature; bereavement support through group sessions, art therapy and one-to-one counselling/therapy; virtual sessions on planning for the future.

2. Social isolation - Telephone befriending and virtual community support groups.

3. Signposting to other services - Information and guidance to help people access other services locally.

Methodology A triage and referral pathway developed through Compton Care Coordination Team to assess and identify the appropriate level of support for either informal, practical or complex support. Step 1 of the service to provide informal support to people in the community:

- Virtual Bereavement Information Hub - opportunity to share experience with others who are affected by loss and grief.

- Telephone befriending - supporting individuals on the telephone for those affected by loneliness and isolation.

- Understanding bereavement workshop - awareness session exploring effects of grief and supporting people who are grieving.

Results Through these methods, we have increased our community reach and supported the following:

- Virtual Bereavement Information Hub $=108$ sessions held/22 people making over 220 visits to a session.

- Telephone befriending $=37$ people and over 200 calls made.

- Understanding bereavement workshops = $12 \mathrm{held} / 78$ participants. 